\title{
Gastrointestinal and biliary granular cell tumor: diagnosis and management
}

\author{
Mohamed Barakat ${ }^{a}$, Abdullah Abu Karb, Seyedmohammad Pourshahidc, Sanaz Ainechid, \\ Hwa Jeong Lee ${ }^{d}$, Mohamed Othmane, Micheal Tadros ${ }^{f}$
}

Queens Hospital Center, NY; Albany Medical Center, NY; Icahn School of Medicine, Queens Hospital Center, NY; Baylor College of Medicine, Houston, TX, USA

\section{Abstract}

\begin{abstract}
Granular cell tumors (GCTs) are generally thought to be of Schwann cell origin and are typically S-100 positive. Up to $11 \%$ of these tumors affect the gastrointestinal tract, most commonly the esophagus, colon, and stomach. While GCTs are mostly benign, malignant and metastatic GCTs have been reported. GCTs are usually found incidentally during esophagogastroduodenoscopy, colonoscopy, imaging studies or during the evaluation of non-specific symptoms. Endoscopically, they are typically yellow in appearance with intact mucosa. On endoscopic ultrasound, they usually are hypoechoic, homogenous, smooth-edged lesions that appear to originate from the submucosal layer, although other endoscopic and ultrasound appearances have been described. There is no consensus on how to treat GCT. Surgical and conservative approaches have been described in the literature. GCTs can also affect the biliary tract, where patients may be misdiagnosed with cholangiocarcinoma. We explore the epidemiology, histology, clinical presentation, diagnosis and treatment of these tumors in the gastrointestinal tract, including the pharynx, esophagus, stomach, small intestine, large intestine and the perianal region. In addition, GCTs in the biliary tract are reviewed.
\end{abstract}

Keywords Granular cell tumor, gastrointestinal tumors, biliary tract

Ann Gastroenterol 2018; 31 (4): 1-9

\section{Introduction}

Granular cell tumors (GCTs) were first described by Abrikossoff, in a series of 5 tumors of the tongue [1]. He believed they were of skeletal muscle origin. Hence, their original name was "granular cell myoblastoma". Ultrastructural and immunohistochemical studies, including the fact they

Departments of a Internal Medicine, Icahn School of Medicine - Queens Hospital Center, NY (Mohamed Barakat); ' Internal Medicine, Albany Medical Center, Albany, NY (Abdullah Abu Kar); ' Internal Medicine, Icahn School of Medicine - Queens Hospital Center, NY

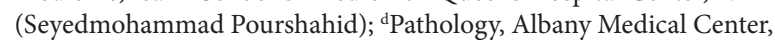

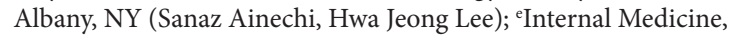
Division of Gastroenterology, Baylor College of Medicine, Houston, TX (Mohamed Othman); f Internal Medicine, Division of Gastroenterology, Albany Medical Center, Albany, NY (Micheal Tadros), USA

Conflict of Interest: None

Correspondence to: Micheal Tadros, MD, MPH, Assistant Professor of Medicine, Department of Medicine, Division of Gastroenterology, Albany Medical Center, 47 New Scotland Avenue, MC 48, Albany, NY 12208, USA, e-mail: tadrosm1@mail.amc.edu

Received 16 January 2018; accepted 26 March 2018; published online 9 May 2018

DOI: https://doi.org/10.20524/aog.2018.0275 are typically S-100 positive, suggest that these tumors are of Schwann cell origin [2]. Tumors that lack S-100 positivity were first described in 1991 as non-neuronal GCTs [3]. In an attempt to trace the origin of GCTs, Vered et al used a broad panel of antibodies [4]. Their immuno-profile did not confirm any particular cell type for the histogenetic origin of GCTs. GCTs most commonly affect the tongue, skin and subcutaneous tissue [5]. Five to $11 \%$ of all GCTs are found in the gastrointestinal tract (GIT), where they mostly affect the esophagus, colon, or stomach [6,7].

Given the rarity of this disease and the limited data, we explore the epidemiology, histology, clinical presentation, diagnosis and treatment of these tumors in the GIT, including the pharynx, esophagus, stomach, small intestine, large intestine and the perianal region. In addition, GCTs in the biliary tract are reviewed. Fig. 1 shows the incidence of gastrointestinal GCTs by location.

\section{Materials and methods}

A systematic literature search was conducted using PubMed and the Cochrane Library from inception until June $30^{\text {th }}$, 2017. The search terms "Granular Cell Tumor" and "GCT" were combined with each of the following terms: 
"Gastrointestinal", "Pharynx", "Pharyngeal”, "Esophagus", "Esophageal”, “Stomach", “Gastric”, "Duodenum”, “Duodenal”, "Small intestine", "Large intestine", "Colon", "Rectum", "Colorectum", "Colorectal", "Anus", "Anal”, "Perianal”, "Biliary” and "Gall bladder". A total of 991 results were obtained. After irrelevant, duplicate, and non-English articles had been excluded, 202 remaining articles were reviewed. These articles included literature reviews, case reports and therapeutic options.

\section{General epidemiology}

GCTs are uncommon soft tissue tumors. Lack et al reviewed 410,000 surgical specimens over 32 years at one institution and found the overall incidence of GCTs to be $0.03 \%$ [5]. They can affect virtually any organ and all age groups, but most commonly occur in the tongue, skin and subcutaneous tissue during the fourth, fifth, and sixth decades of life [5]. GCTs mostly occur as solitary tumors but $7-25 \%$ of cases involve multiple tumors [8]. These are mostly benign tumors that remain biologically quiescent for a long period of time. Fewer than $2 \%$ of cases are malignant and recurrence after adequate surgical resection can reach $8 \%$ [3].

Five to $11 \%$ of all GCTs occur in the GIT [6], where the three most commonly affected organs are the esophagus, colon, and stomach, with rates of $65 \%, 20 \%$ and $9 \%$, respectively, of all GIT GCTs (Fig. 1) [6,9]. According to a study by An et al, gastric and colorectal GCTs tend to be larger than esophageal GCTs, with average sizes of $0.75 \mathrm{~cm}, 0.6 \mathrm{~cm}$ and $0.27 \mathrm{~cm}$, respectively [9].

\section{Histopathology}

GCTs in different locations have similar histopathological features and are mostly covered by normal mucosa [10,11]. Histologically, GCTs are composed of either nests or sheets of plump epithelioid or spindle cells (or both) with a small, round nucleus. The cells have abundant granular eosinophilic cytoplasm (representing phagolysosomes) [12]. These tumors are generally positive for S-100 and neuron-specific enolase, which is suggestive of a Schwann cell origin. The histological features of GCT are very characteristic. Thus, only a small number of cells are necessary for diagnosis [13]. Although not common, S-100 negative GCT has been reported and represents an entity called non-neural GCTs [14]. Fig. 2A,B show the histological characteristics of GCTs.

Generally, GCTs in the GIT appear histologically similar to GCTs elsewhere. However, colorectal GCTs tend to have more nuclear atypia, which does not necessarily correlate with a malignant behavior [15]. Colonic and gastric GCTs show more peritumoral lymphoid cuffs and infiltrative growth patterns than esophageal GCTs. Immunohistochemically, gastrointestinal GCTs are positive for S-100 protein (100\%), CD56 (95\%), CD68 (95\%), SOX-10 (93\%), and

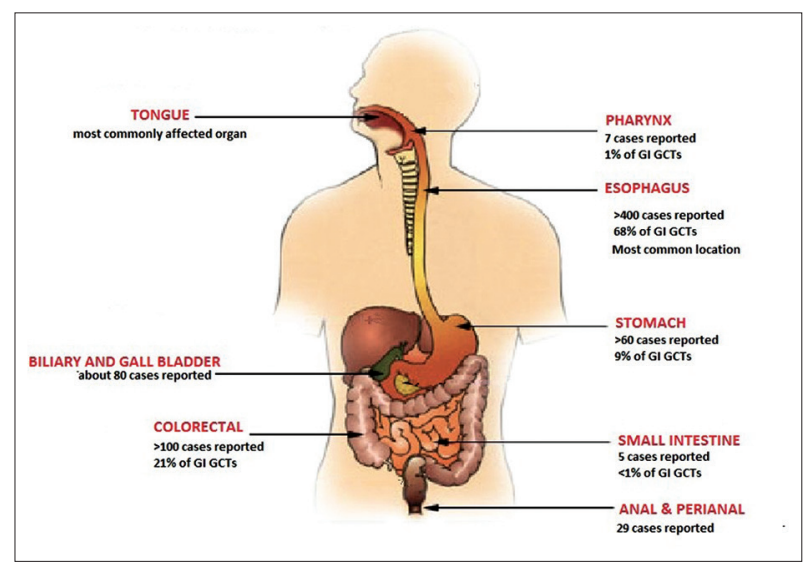

Figure 1 Incidence of gastrointestinal granular cell tumors by location

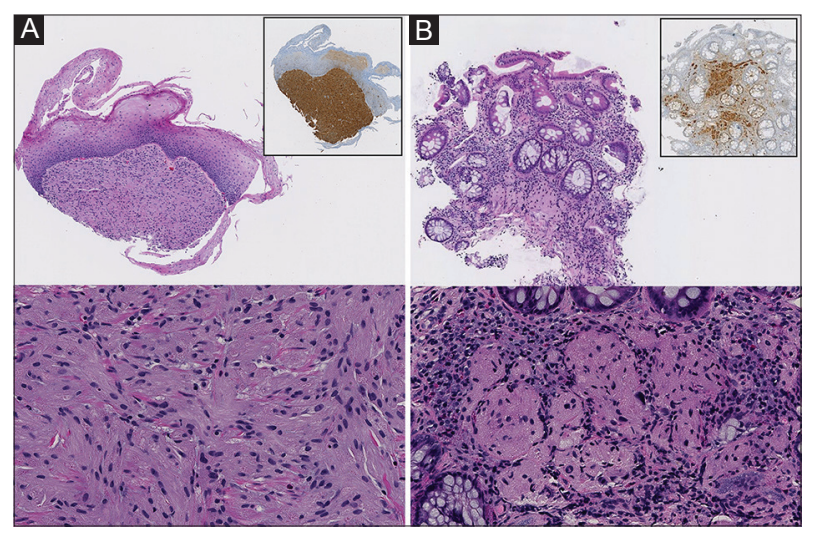

Figure 2 (A) Esophageal granular cell tumor (GCT). The upper panel shows a scanning view of a GCT in the submucosa (hematoxylin and eosin, original magnification $\times 50$; inset: S-100 immunostain), while the high magnification view (lower panel) demonstrates sheets of polygonal to spindly cells with abundant granular cytoplasm and bland, small nuclei (hematoxylin and eosin, original magnification $\times 300$ ). (B) Granular cell tumor in the colon. The upper panel shows a scanning view of a colon biopsy with epithelioid cells in the mucosa (hematoxylin and eosin, original magnification $\times 50$; inset: S-100), while higher magnification (lower panel) shows a proliferation of epithelioid cells with abundant granular cytoplasm and pyknotic nuclei (hematoxylin and eosin, original magnification $\times 300$ )

inhibin- $\alpha(52 \%)[9,16,17]$. Table 1 shows the special and immunohistochemical stains used for the diagnosis of GCTs $[18,19]$.

While GCTs are most often benign, vascular invasion is not uncommon in benign GCTs. Although rare, malignant GCTs have been described in the literature. Proposed histologic criteria for malignant GCTs by Fanburg-Smith et al include tumor necrosis, tumor cell spindling, pleomorphism, high nuclear to cytoplasmic ratio, large nucleoli, and increased mitotic activity (more than 2 mitoses per 10 high-power fields at $\times 200$ magnification) [20]. Tumors that meet at least 3 of these criteria are classified as malignant, while tumors meeting one or two criteria are classified as atypical. However, there are reports of metastasis in patients with histologically benign GCTs [21]. Therefore, the tumor's cytological features are less 
important than evidence of metastases and the infiltrative growth pattern in evaluating for malignancy. There are two types of malignant GCTs: those histologically and clinically malignant; and those histologically benign but clinically malignant [22]. Malignant GCTs may also be larger in size $(>4 \mathrm{~cm})[23]$.

GCTs can induce pseudoepitheliomatous hyperplasia of overlying squamous epithelium, which can lead to a misdiagnosis of squamous cell carcinoma if the biopsy is superficial [24]. In one study [5], 9\% of GCTs show pseudoepitheliomatous hyperplasia on biopsy, while another study reported that approximately 50\% of GCTs in the esophagus and perianal region showed varying degrees of pseudoepitheliomatous hyperplasia [6]. Therefore, it is advisable to obtain as many samples as possible for histologic diagnosis. Pseudoepitheliomatous hyperplasia is unlikely to occur in the stomach, small or large bowel.

\section{Gastrointestinal GCTs by location}

\section{Pharynx}

Pharyngeal GCTs are extremely rare. To the best of our knowledge, seven known cases with no malignant tumors have been reported $[11,25]$. In these 7 cases, 5 patients originally presented with dysphagia, at times accompanied by dysphonia and dyspnea, and two presented with globus. Tumors were found on endoscopy or imaging and all were excised. The diagnosis was reached after histological examination of the mass. No evidence of recurrent disease was found in any patient during the post-treatment follow up, which ranged from 4 months to 5 years [11].

\section{Esophagus}

\section{Epidemiology}

The esophagus is the most commonly affected gastrointestinal organ: it accounts for $1.7 \%$ of all GCTs [5] and approximately $1.2 \%$ of all esophageal tumors [26]. Based on our literature review, over 400 cases have been reported in the literature, accounting for almost two thirds of gastrointestinal GCTs. The prevalence of GCTs increases distally with over $50 \%$ of the cases involving the distal esophagus $[5,13,27]$. These tumors are mostly found incidentally on esophagogastroduodenoscopy (EGD).

\section{Clinical presentation}

Esophageal GCTs are most often asymptomatic and are found incidentally during EGD. Patients with lesions less than $2 \mathrm{~cm}$ in size are more likely to be asymptomatic [7]. If symptomatic, they can present with symptoms mimicking gastroesophageal reflux disease. Patients with cervical esophageal GCT most commonly present with dysphagia [24]. However, dysphagia often has another etiology [13].

\section{Endoscopic appearance}

On endoscopy, a GCT typically appears as a yellow firm lesion with intact mucosa [7]. However, Zhong et al found that only $26 \%$ of patients present with this typical appearance [13]. Esophageal GCTs can also be red or white-gray $[7,13,28]$. Rarely, ulcerated tumors are observed on the mucosal surface [7]. Fig. 3A-C show different endoscopic appearances of esophageal GCTs.

Table 1 Special stains and immunohistochemical stains used for diagnosis of granular cell tumor

\begin{tabular}{ll}
\hline Special stain & PAS \\
& $\begin{array}{l}\text { Acid } \\
\text { phosphatase } \\
\text { Luxol fast blue }\end{array}$ \\
& S-100 \\
Immunostain & NSE \\
& Vimentin \\
& CD68 \\
& CD56 \\
& CD57 \\
& SOX-10 \\
& Nestin \\
& Inhibin- ${ }^{*}$ \\
\hline${ }^{*}$ Inhibin- $\alpha$ stain may be specific for granular cell tumor of the biliary \\
tree $[18,19]$ \\
NSE, neuron-specific enolase
\end{tabular}

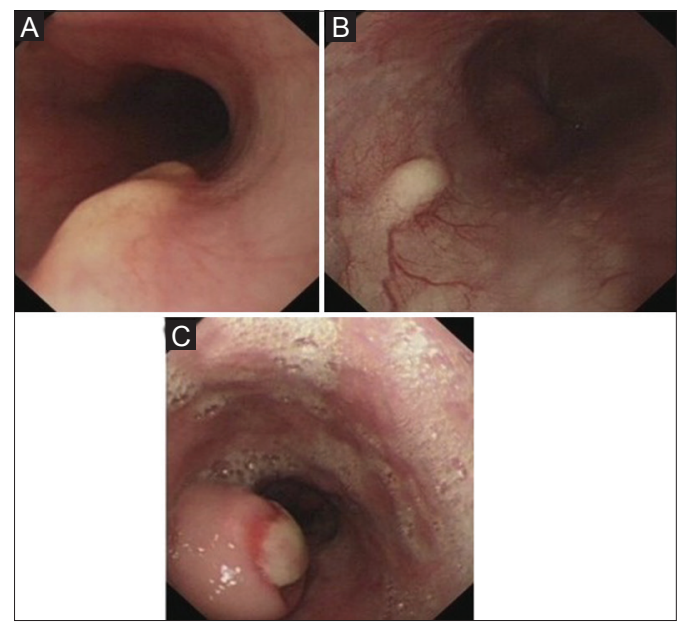

Figure 3 (A-C) Endoscopic appearances of esophageal granular cell tumors 


\section{Endoscopic ultrasound (EUS)}

EUS is the best procedure to evaluate upper gastrointestinal submucosal lesions [29]. Esophageal GCTs are typically hypoechoic, homogeneous, and smooth-edged lesions [13,28]. Nonetheless, GCT can be hyperechoic, heterogeneous and have irregular margins. GCTs typically appear to arise from the submucosal layer; however, EUS can show if the tumor involves or originates from muscularis propria [13]. EUS should be performed on all patients with esophageal GCT as both tumor size and the degree of invasion are important to determine the method of treatment [30,31]. For instance, endoscopic resection should not be used in the management of tumors attached to muscularis propria. EUS and endoscopic features together can distinguish GCTs from lipomas, esophageal cysts and inflammatory polyps, but may not be able to distinguish between leiomyomas located in the muscularis mucosa or propria and GCTs located in the muscularis propria [7]. Fig. 4 shows EUS findings of esophageal GCTs.

\section{Diagnosis}

Standard endoscopic forceps biopsy is sufficient to obtain the diagnosis in $50-83 \%$ of cases $[13,30]$. Endoscopic mucosal resection (EMR), EUS-guided Tru cut biopsy and EUS-guided fine-needle aspiration may also be used [13]. A literature review of cervical esophageal GCT found that minimally invasive diagnostic techniques had been used in 8 patients. Success rates of $50 \%$ and $75 \%$ were achieved by endoscopic and radiographic needle biopsy interventions, respectively [24]. The differential diagnosis for GCT includes leiomyoma, cystic lesions, metastasis, GI stromal tumor, and other primary neoplasms. In a study published by Palazzo et al, EUS was performed on 15 patients with 21 lesions thought to be compatible with esophageal GCT by endoscopy, but unconfirmed by biopsy [30]. Typical sonographic features were observed in $95-100 \%$ of the cases, and histopathology confirmed the diagnosis of GCT for all 21 lesions after their removal. In another study, Lee et al

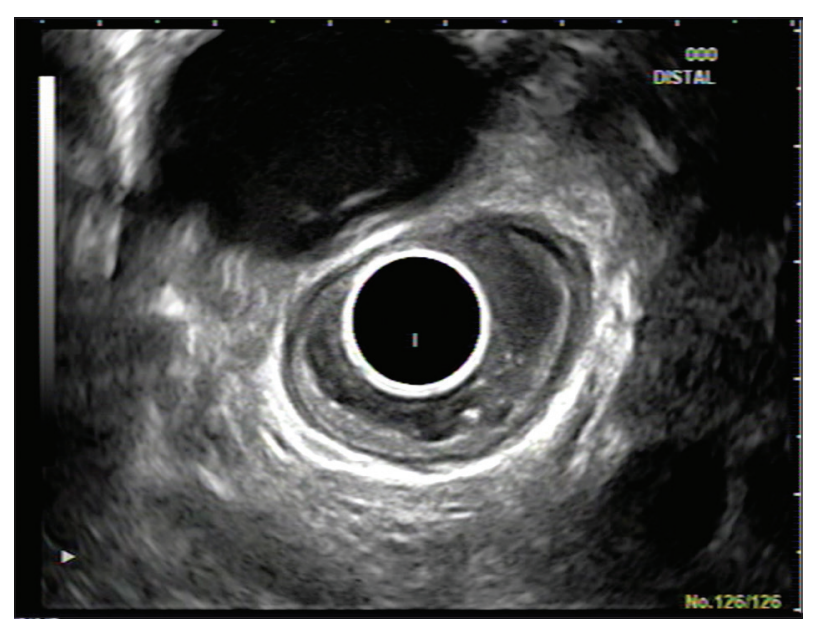

Figure 4 Endoscopic ultrasound findings of an esophageal granular cell tumor. Hypoechoic, smooth, homogenous mass found that EUS identified 13 of 14 cases of GCT before they were confirmed histologically [32]. These studies highlight the importance of EUS in the diagnosis of esophageal GCT.

\section{Management}

The treatment of esophageal GCT is still controversial because of its rarity. Whether these tumors need to be monitored endoscopically for changes in size or immediately removed is often unclear [13]. If removal is necessary, endoscopic treatment is less invasive, cheaper, and poses fewer complications; it is therefore increasingly being used as an alternative to traditional surgical resection [23].

Monitoring can be achieved by periodic endoscopy and biopsies. In a review of 52 new cases of esophageal GCT between 1988 and 1994, only one of 17 patients had tumor enlargement, with no malignancy detected on follow up. The authors suggested that periodic monitoring is the most effective way to treat patients with esophageal GCT [27].

\section{EMR}

A cohort study of 14 patients by Chen et al recommended the use of EMR for lesions less than $2 \mathrm{~cm}$ in diameter; alternatively, submucosal tunnel endoscopic resection can be used for tumors with a diameter between 2 and $3 \mathrm{~cm}$ [7]. Surgical removal with traditional open surgery or videoassisted thoracoscopic surgery was recommended for tumors with a high suspicion of malignancy, tumors originating from muscularis propria, or tumors with a diameter greater than $3 \mathrm{~cm}$ [7]. Suggested criteria for EMR by Yasuda et al include: tumor size $<2 \mathrm{~cm}$, no attachment to muscularis propria, and absence of anatomo-pathological malignity criteria [31]. Epinephrine can be injected into submucosa to separate the superficial mucosa from muscularis propria, thereby raising the neoplasm and decreasing the risk of perforation and bleeding during the procedure. In one study by Nie et al, after EMR was performed on 12 patients with esophageal GCT only 1 patient developed bleeding, which was managed successfully by endoscopic hemostasis [33]. Various nonconventional EMR techniques have been used in the treatment of esophageal GCT, including EMR using a transparent cap (EMR-C), EMR with a ligation device (EMR-L), and strip biopsy [32,34,35]. Kahng et al found that, among 18 patients with esophageal GCT treated with EMR or EMR-L, 2 patients had minor bleeding and 1 had active bleeding that was stopped after endoscopic hemostasis with hemoclips and electrocoagulation [36]. Other complications included mild chest or abdominal discomfort in 5 patients that subsided within one or two days. This favorable side effect profile was accompanied by a $92.6 \%$ success rate in achieving complete resection of the tumor. In another study by Wehrmann et al, endoscopic resection of a submucosal esophageal tumor was found to cause bleeding in $40 \%$ of patients, requiring endoscopic hemostasis [37]. Techniques of endoscopic resection include rubber band followed by resection with a snare, simple snare resection "lift-and-cut" 
and cap resection. EMR can be safe and effective in the removal of esophageal GCT [38].

\section{Endoscopic submucosal dissection (ESD)}

Nie et al reported that, when ESD was used to treat 17 patients with esophageal GCTs, only one developed bleeding, which was managed by endoscopic hemostasis [33]. In a study by Lu et al, ESD was performed on 14 patients with esophageal GCT with no complications [39]. ESD using Clutch Cutter $^{\oplus}$ (Fujifilm Corporation, Odawara, Japan) was described with no complications for submucosal tumors that had not invaded the muscularis propria [26]. EUS can be used to ensure complete removal of GCTs after submucosal endoscopic resection. Submucosal endoscopic resection can be safe and effective in the management of esophageal GCT. However, submucosal endoscopic resection is not safe for tumors located in the muscularis propria [7]. Fig. 5 shows ESD of a GCT.

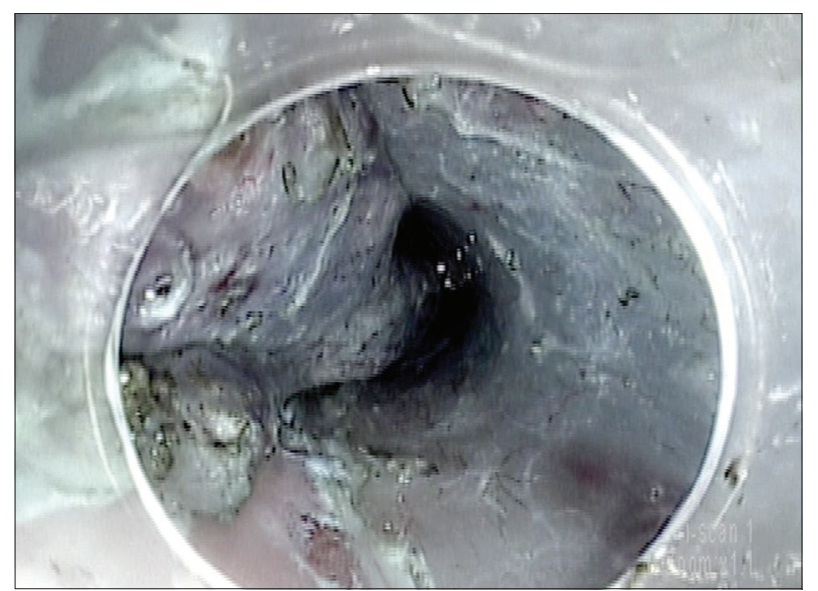

Figure 5 Endoscopic submucosal dissection of a distal esophageal granular cell tumor

\section{Surgery}

Surgical treatment should be reserved for patients with suspicion of malignancy, contraindications for endoscopic dissection, or multiple symptomatic tumors. Huang et al recommended surgery for cervical esophageal GCTs, even if asymptomatic, because these tumors can affect vital structures, such as the recurrent laryngeal nerve, larynx and pharyngeal constrictor muscles [24]. Tumor growth may also be associated with increased morbidity from surgical removal. The same review suggested endoscopy or imaging of the upper GIT to exclude secondary lesions, given the high rate of concurrent lesions with cervical esophageal GCT.

Other proposed forms of treatment include dehydrated alcohol injection, polidocanol, and Yttrium-aluminum-garnet laser ablation [40-42]. A major advantage of endoscopic resection over these treatment modalities is the ability to obtain tissue for diagnostic purposes. Fig. 6 depicts the suggested approach and management for esophageal GCTs.

\section{Prognosis}

Esophageal GCT has a favorable prognosis. Zhong et al found that there were no malignant tumors in a cohort of 23 patients [13]. This is consistent with a study of 44 cases in The Netherlands [27]. Although the tumor is mostly benign, there are reports of infiltrative and metastatic esophageal GCTs [43].

In summary, the esophagus is the gastrointestinal organ most commonly affected by GCTs, which are mostly found incidentally on endoscopy but can present with nonspecific symptoms. On endoscopy, they mostly appear yellow with intact mucosa. EUS typically shows hypoechoic, homogenous and smooth-edged lesions. Treatment options include monitoring, endoscopic resection, and surgical removal. The tumor is mostly benign, but there are reports of malignant and metastatic cases.

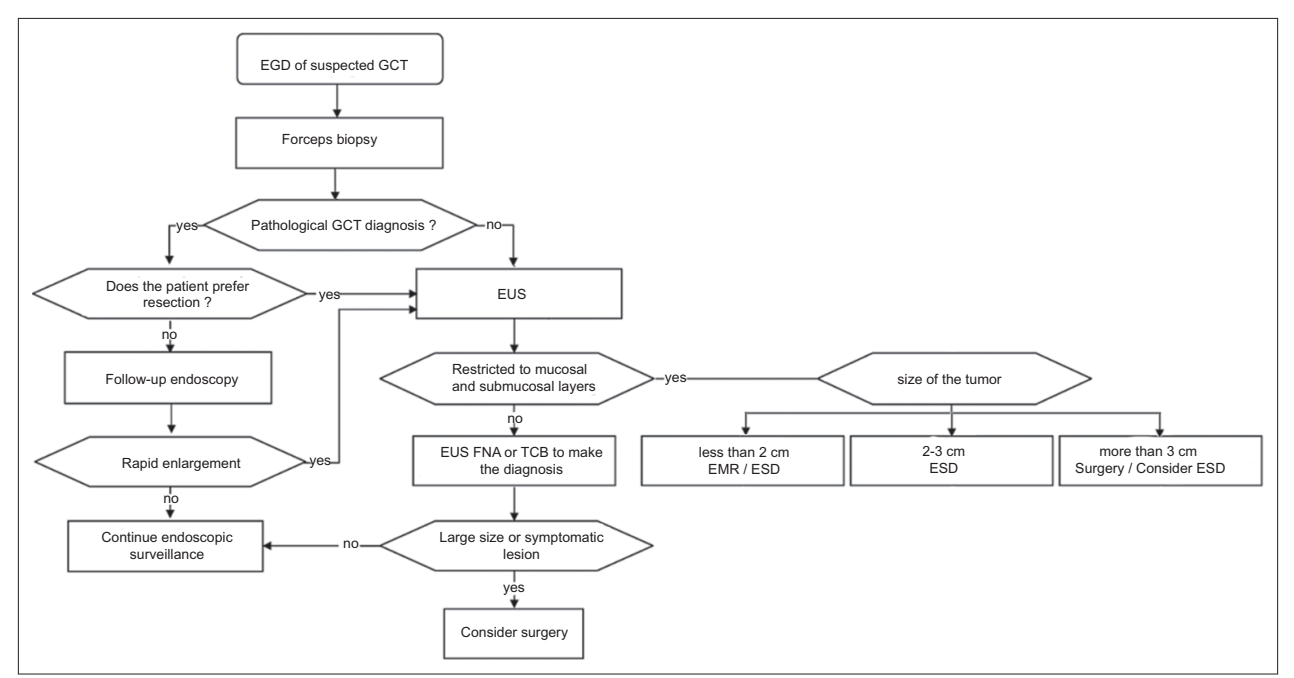

Figure 6 Algorithm of a suggested approach for management of esophageal granular cell tumor 


\section{Stomach}

The stomach is the third most commonly affected gastrointestinal organ. There are over 60 reported cases in the literature, representing 9\% of all gastrointestinal GCTs [44]. Most patients are of African-American or Asian ethnicity. Gastric GCTs are more common in the upper part of the stomach and are associated with a synchronous esophageal location in $50 \%$ of cases. However, GCTs have been reported in multiple locations, including, but not limited to, the pylorus, cardia, lesser curvature, fundus, and gastroesophageal junction. Gastric GCTs are generally benign; however, malignant gastric GCT has been reported [45]. Gastric GCT may coexist with gastric carcinoma but this is probably a casual association.

Like esophageal GCTs, gastric GCTs are mostly found incidentally on abdominal imaging, upper endoscopy, or during abdominal surgery. If symptomatic, patients usually present with abdominal pain [46]. The presenting symptoms may even mimic peptic ulcer disease. If the tumor is large, it can present with massive gastrointestinal bleeding or gastric outlet obstruction [46,47].

The endoscopic and ultrasonographic features of gastric GCTs are similar to those of esophageal GCTs, with most lesions appearing yellow and submucosal on EGD. On EUS, lesions are typically hypoechoic and regular. Diagnosis can be achieved by endoscopic biopsy through boring, or by performing a jumbo biopsy. However, up to $50 \%$ of the cases may not be conclusive, because it can be challenging to endoscopically distinguish gastric GCT from other submucosal tumors, including carcinoid tumors, lipomas, and GI stromal tumors. Although the majority of GCTs occur after the fourth decade, gastric GCT has also been reported in young patients [48].

As with all gastrointestinal GCTs, there is no consensus on treatment because of the rarity of these lesions. Surgical excision has been a common modality for treatment of gastric GCT [49,50]. However, Kahng et al reported 5 cases of gastric GCT treated with EMR, EMR-L or ESD with no complications [36]. Follow up for 12-31 months did not reveal any recurrence in their cohort. There is a reported case where standard EMR failed, but endoscopic removal using Duette Multiband Mucosectomy Kit (Cook Ireland Ltd.; Limerick, Ireland) was performed successfully [51].

\section{Small intestine}

Small intestine GCTs are extremely rare. We found very few reported cases of GCT in the duodenum and ileum in our literature search $[6,52,53]$. There were no reported cases involving the jejunum. Patients with duodenal GCT presented with upper GI bleeding or abdominal discomfort. The clinical presentation of ileal GCTs was not described.

In a case of duodenal GCT, the tumor was identified endoscopically. Biopsy showed normal duodenal histology that was later explained by the biopsy not involving the submucosal layer [52]. In that patient, EUS was used and demonstrated an oval anechoic lesion with largest diameter $5 \mathrm{~mm}$. This again highlights the importance of EUS in the evaluation of gastrointestinal GCT. In another case, endoscopy showed a submucosal tumor with overlying ulceration [53].

One patient with duodenal GCT underwent duodenectomy because of GI bleeding, while another patient was treated conservatively. Treatment should be tailored to each case, based on the nature of the individual's disease.

There are insufficient data to predict the prognosis of small intestinal GCT. However, it might be expected to have a favorable prognosis, similar to GCTs in other locations.

\section{Colorectum}

Endoscopic and ultrasonographic features of colorectal GCTs are similar to those reported for esophageal and gastric GCTs. Colorectal GCTs may be located anywhere between the rectum and the cecum, with nearly $20 \%$ of all gastrointestinal GCTs occurring in the colorectal region. There are over 100 cases of colorectal GCTs reported in the literature, making it the second most affected organ in the GIT after the esophagus [10]. Sixty-three to $73 \%$ of colorectal GCTs affect the right colon (cecum and ascending colon) [15]. GCT can involve the appendix, with equal distribution between midappendix and tip [54]. Sobel et al found granular cells in 5\% of their routine appendectomy specimens [55].

Like most other GCTs, colorectal GCTs are mostly found incidentally as a solitary submucosal tumor during colonoscopy. Johnston et al reported that 17 of 20 colorectal GCTs were found incidentally during investigations of the colon for alternative indications [6]. In other cases, patients presented with hematochezia, abdominal pain, loose stool or constipation [10]. When GCT involves the appendix, patients can present with appendicitis [39]. GCT can also be detected incidentally during major abdominal surgery [54]. Interestingly, Saleh et al reported a case of multiple synchronous GCTs involving the colon, appendix, and mesentery [23].

As with esophageal GCT, colorectal GCTs usually appear as small yellow submucosal tumors. Endoscopically, colonic GCTs may resemble sessile polyps or, less frequently, pedunculated polyps. Most lesions are small $(<2 \mathrm{~cm})$. Patients may have additional findings on colonoscopy, including adenomas and hyperplastic polyps, which are likely unrelated to the presence of GCT [10].

The diagnostic workup includes colonoscopy, EUS, and biopsy. EUS features are similar to those of esophageal GCT. Colorectal GCTs can have marginal or infiltrative growth patterns, with a subset displaying reactive mucosal surface changes, nuclear pleomorphism, a lymphoid cut or focal calcification. The surface changes can be so pronounced that they can result in misdiagnosis as tubular adenomas or adenocarcinoma on colorectal mucosal biopsies [7]. Therefore, diagnosing colorectal GCT may be challenging even with a biopsy. While GCTs overall are usually not infiltrative, more than $50 \%$ of colorectal GCTs show an infiltrative growth pattern $[7,10]$. Malignant GCT of the colon has been reported [36]. 
EUS is a valuable diagnostic tool to determine echogenicity and depth of invasion. Typical EUS findings show a hypoechoic and homogenous mass. However, EUS cannot always be used to distinguish benign from malignant tumors [10].

There are currently no standard treatment guidelines for colorectal GCT; however, an approach similar to that suggested for esophageal GCT may be used. Colonic GCTs less than $2 \mathrm{~cm}$ can be treated by EMR or EMR-C [31]. Endoscopic mucosal resection and polypectomy are effective treatment options that have had no complications in over $70 \%$ of cases. Interestingly, Melo et al reported a case of 52 GCTs involving the entire colon from the cecum to the sigmoid [56]. The authors suggested that, in such cases, a conservative approach with long periods of observation and repeated colonoscopy may be most appropriate. If GCT involves the appendix, laparoscopic appendectomy may be indicated, as the majority of these cases typically present with appendicitis [54]. We suggest a similar treatment approach to the algorithm for esophageal GCT shown in Fig. 6. Although endoscopic resection is curative in most cases, local recurrence has been reported, especially if the tumor was not completely excised $[5,10]$.

\section{Perianal}

GCT of the perianal region is rare, with approximately 30 cases described in the literature [30]. The most common clinical presentation is the presence of an asymptomatic mass found incidentally during the evaluation of perianal disorders such as hemorrhoids and fissures [6]. Patients may present with anal pain, discomfort, and bleeding $[57,58]$. The tumor can also be found as a polypoid mass in the anus [59]. Polypoid lesions in the anal canal are mostly malignant; benign anal mesenchymal tumors are relatively rare. GCTs can affect both internal and external anal sphincters and can be mistakenly diagnosed as perianal abscesses [6].

Pseudoepitheliomatous hyperplasia is more common in perianal GCT than in other gastrointestinal locations, leading to a higher chance of misdiagnosis as squamous cell carcinoma. The differential diagnosis includes perianal abscess, granuloma, and malignant tumor [60]. Surgical excision is needed for the diagnosis and treatment of perianal GCTs. Although mostly benign, there are reports of malignant GCT in the anal canal [55].

\section{Biliary}

Nearly 80 cases of biliary tract and gallbladder GCT have been reported in the literature. Biliary GCTs represent less than $1 \%$ of all GCTs [61]. The first report of a biliary GCT was by Coggins in 1952, during the autopsy of a patient with alleged Laennec's cirrhosis [62]. The biliary tract is more likely to be affected than the gallbladder [63]. Over half of the reported cases occurred in African-American females [64] with a median age of 34 years, which is less than the typical age of patients with gastrointestinal GCT. Despite its rarity, GCT is the most common benign non-epithelial tumor of the extrahepatic biliary tract. Nonetheless, GCTs are rarely diagnosed preoperatively [65]. They are most commonly found in the common bile duct (58.1\%) and common hepatic duct (23.3\%), and less commonly in the cystic duct (14.0\%), gallbladder and ampulla of Vater (2.3\%) [66]. Bilanovic et al described a case of acalculous cholecystitis caused by a GCT [65].

Biliary tract GCT typically presents with symptoms of biliary obstruction, but can also be found incidentally on radiographic studies. Most patients complain of jaundice (44.4\%), abdominal pain (34.6\%) or both (11.1\%) [64-66]. Radiologic findings of intra- and/or extrahepatic dilation can be seen and may lead to a misdiagnosis of choledochal cyst [61]. Diagnosis prior to removal is challenging. However, GCT of the bile duct can be diagnosed on endoscopic brushing and should be considered in the cytological differential diagnosis in the appropriate clinical settings [67]. Endoscopic brushing should be considered for larger lesions with associated breaks in the mucosal surface for adequate evaluation and to increase the diagnostic yield. The differential diagnosis includes choledochal cyst, cholangiocarcinoma, biliary stricture, primary sclerosing cholangitis, polyps, papillomas and adenomas.

Because of its tendency to mimic cholangiocarcinoma, many patients with GCT are treated with extensive surgical procedures $[61,65]$. Suggested treatments include percutaneous or endoscopic stents for temporary decompression, or surgical excision with tumor-free margins followed by hepaticojejunostomy. There are reports of patients with biliary GCTs treated with cholecystectomy, choledochoenterostomy, hepaticoenterostomy, and pancreaticoduodenectomy [68]. Treatment should be tailored to the location of the tumor and tumor-free margins are recommended to decrease the risk of recurrence [69]. These lesions can cause obstruction of the bile duct by concentric narrowing, which may lead to secondary biliary cirrhosis if left untreated, and will possibly require liver transplantation [69]. Based on the findings of this review, no malignant GCT of the biliary tract has been reported.

\section{Concluding remarks}

GCTs mostly affect the skin, tongue, and subcutaneous tissue. Five to $11 \%$ of GCTs are found in the GIT, most commonly affecting the esophagus, colorectum, and stomach. When possible, EUS and pathologic samples are needed for diagnosis and treatment. Decision regarding treatment is often based on tumor size, symptoms, and patient choice and may include observation, EMR, ESD, or surgery. Further investigations of randomized controlled studies are required to evaluate the optimal treatment for GCTs.

\section{References}

1. Abrikossoff AI. Über myome ausgehend von der quergestreiften willkürlichen muskulatur. Virchows Arch Path Anat 1926;260:215-233.

2. Stefansson K, Wollmann R, Jerkovic M. S-100 protein in soft-tissue tumors derived from Schwann cells and melanocytes. Am J Pathol 
1982;106:261-268.

3. LeBoit PE, Barr RJ, Burall S, Metcalf JS, Yen TS, Wick MR. Primitive polypoid granular-cell tumor and other cutaneous granular-cell neoplasms of apparent nonneural origin. Am J Surg Pathol 1991;15:48-58.

4. Vered M, Carpenter WM, Buchner A. Granular cell tumor of the oral cavity: updated immunohistochemical profile. J Oral Pathol Med 2009;38:150-159.

5. Lack EE, Worsham GF, Callihan MD, et al. Granular cell tumor: a clinicopathologic study of 110 patients. J Surg Oncol 1980;13:301-316.

6. Johnston J, Helwig EB. Granular cell tumors of the gastrointestinal tract and perianal region: a study of 74 cases. Dig Dis Sci 1981;26:807-816.

7. Chen WS, Zheng XL, Jin L, Pan XJ, Ye MF. Novel diagnosis and treatment of esophageal granular cell tumor: report of 14 cases and review of the literature. Ann Thorac Surg 2014;97:296-302.

8. Apisarnthanarax P. Granular cell tumor. An analysis of 16 cases and review of the literature. J Am Acad Dermatol 1981;5:171-182.

9. An S, Jang J, Min K, et al. Granular cell tumor of the gastrointestinal tract: histologic and immunohistochemical analysis of 98 cases. Hum Pathol 2015;46:813-819.

10. Singhi AD, Montgomery EA. Colorectal granular cell tumor: a clinicopathologic study of 26 cases. Am J Surg Pathol 2010;34:1186-1192.

11. Piazza C, Casirati C, Peretti G, Battaglia G, Manfredini C, Nicolai P. Granular cell tumor of the hypopharynx treated by endoscopic $\mathrm{CO}(2)$ laser excision: report of two cases. Head Neck 2000;22:524-529.

12. Parfitt JR, McLean CA, Joseph MG, Streutker CJ, Al-Haddad S, Driman DK. Granular cell tumours of the gastrointestinal tract: expression of nestin and clinicopathological evaluation of 11 patients. Histopathology 2006;48:424-430.

13. Zhong N, Katzka DA, Smyrk TC, Wang KK, Topazian M. Endoscopic diagnosis and resection of esophageal granular cell tumors. Dis Esophagus 2011;24:538-543.

14. Lerman M, Freedman PD. Nonneural granular cell tumor of the oral cavity: a case report and review of the literature. Oral Surg Oral Med Oral Pathol Oral Radiol Endod 2007;103:382-384.

15. Na JI, Kim HJ, Jung JJ, et al. Granular cell tumours of the colorectum: histopathological and immunohistochemical evaluation of 30 cases. Histopathology 2014;65:764-774.

16. Mazur MT, Shultz JJ, Myers JL. Granular cell tumor. Immunohistochemical analysis of 21 benign tumors and one malignant tumor. Arch Pathol Lab Med 1990;114:692-696.

17. Kurtin PJ, Bonin DM. Immunohistochemical demonstration of the lysosome-associated glycoprotein CD68 (KP-1) in granular cell tumors and schwannomas. Hum Pathol 1994;25:1172-1178.

18. Ensari A. Granular cell tumor: What's new in diagnosis and treatment? Turk J Gastroenterol 2007;18:135-138.

19. Perçinel S, Savaş B, Yilmaz G, et al. Granular cell tumor of the esophagus: three case reports and review of the literature. Turk $J$ Gastroenterol 2008;19:184-188.

20. Fanburg-Smith JC, Meis-Kindblom JM, Fante R, Kindblom LG. Malignant granular cell tumor of soft tissue: diagnostic criteria and clinicopathologic correlation. Am J Surg Pathol 1998;22:779-794.

21. Ordóñez NG, Mackay B. Granular cell tumor: a review of the pathology and histogenesis. Ultrastruct Pathol 1999;23:207-222.

22. Maekawa H, Maekawa T, Yabuki K, et al. Multiple esophagogastric granular cell tumors. J Gastroenterol 2003;38:776-780.

23. Saleh H, El-Fakharany M, Frankle M. Multiple synchronous granular cell tumors involving the colon, appendix and mesentery: a case report and review of the literature. J Gastrointest Liver Dis 2009; 18:475-478.

24. Huang AT, Dominguez LM, Powers CN, Reiter ER. Granular cell tumor of the cervical esophagus: case report and literature review of an unusual cause of dysphagia. Head Neck Pathol 2013;7:274-279.

25. Li X, Parke RB, Rushton JR, Sienko A, Zhai QJ. An unusually large granular cell tumor of the pharynx: a case report and literature review. Int J Clin Exp Pathol 2009;2:300-302.

26. Farrell KH, Devine KD, Harrison EG Jr, Olsen AM. Granular cell myoblastoma of the esophagus. Incidence and surgical treatment. Ann Otol Rhinol Laryngol 1973;82:784-789.

27. Voskuil JH, van Dijk MM, Wagenaar SS, van Vliet AC, Timmer R, van Hees PA. Occurrence of esophageal granular cell tumors in The Netherlands between 1988 and 1994. Dig Dis Sci 2001;46:1610-1614.

28. Zhang M, Sun ZQ, Zou XP. Esophageal granular cell tumor: clinical, endoscopic and histological features of 19 cases. Oncol Lett 2014;8:551-555.

29. Murata Y, Yoshida M, Akimoto S, Ide H, Suzuki S, Hanyu F. Evaluation of endoscopic ultrasonography for the diagnosis of submucosal tumors of the esophagus. Surg Endosc 1988;2:51-58.

30. Palazzo L, Landi B, Cellier C, et al. Endosonographic features of esophageal granular cell tumors. Endoscopy 1997;29:850-853.

31. Yasuda I, Tomita E, Nagura K, Nishigaki Y, Yamada O, Kachi H. Endoscopic removal of granular cell tumors. Gastrointest Endosc 1995;41:163-167.

32. Lee DG, Kim GH, Park DY, et al. Endoscopic submucosal resection of esophageal subepithelial lesions using band ligation. Endoscopy 2011;43:822-825.

33. Nie L, Xu G, Wu H, Huang Q, Sun Q, Fan X. Granular cell tumor of the esophagus: a clinicopathological study of 31 cases. Int J Clin Exp Pathol 2014;7:4000-4007.

34. Shikuwa S, Matsunaga K, Osabe M, et al. Esophageal granular cell tumor treated by endoscopic mucosal resection using a ligating device. Gastrointest Endosc 1998;47:529-532.

35. Takeuchi H, Toda T, Nagasaki S, et al. Strip biopsy to treat esophageal granular cell tumor. J Clin Gastroenterol 1997;25:446-449.

36. Kahng DH, Kim GH, Park DY, et al. Endoscopic resection of granular cell tumors in the gastrointestinal tract: a single center experience. Surg Endosc 2013;27:3228-3236.

37. Wehrmann T, Martchenko K, Nakamura M, Riphaus A, Stergiou N. Endoscopic resection of submucosal esophageal tumors: a prospective case series. Endoscopy 2004;36:802-807.

38. Battaglia G, Rampado S, Bocus P, Guido E, Portale G, Ancona E. Single-band mucosectomy for granular cell tumor of the esophagus: safe and easy technique. Surg Endosc 2006;20:1296-1298.

39. Lu W, Xu MD, Zhou PH, et al. Endoscopic submucosal dissection of esophageal granular cell tumor. World J Surg Oncol 2014;12:221.

40. Moreira LS, Dani R. Treatment of granular cell tumor of the esophagus by endoscopic injection of dehydrated alcohol. Am J Gastroenterol 1992;87:659-661.

41. Maccarini MR, Michieletti G, Tampieri I, Triossi O, Bertinelli E, Casetti T. Simple endoscopic treatment of a granular-cell tumor of the esophagus. Endoscopy 1996;28:730-731.

42. Choi PM, Schneider L. Endoscopic Nd: YAG laser treatment of granular cell tumor of the esophagus. Gastrointest Endosc 1990;36:144-146.

43. Yoshizawa A, Ota H, Sakaguchi N, et al. Malignant granular cell tumor of the esophagus. Virchows Arch 2004;444:304-306.

44. Patti R, Almasio PL, Di Vita G. Granular cell tumor of stomach: a case report and review of literature. World J Gastroenterol 2006;12:3442-3445.

45. Matsumoto H, Kojima Y, Inoue T, et al. A malignant granular cell tumor of the stomach: report of a case. Surg Today 1996;26:119-122.

46. White JG, el-Newihi HM, Hauser CJ. Granular cell tumor of the stomach presenting as gastric outlet obstruction. Am J Gastroenterol 1994;89:2259-2260.

47. Ross JS. Massive upper gastrointestinal hemorrhage from a granular 
cell tumor of the stomach. Am J Gastroenterol 1977;68:595-598.

48. Takaya H, Kawaratani H, Kaneko M, et al. Gastric granular cell tumor in a youth excised by endoscopic submucosal dissection: A case report and literature review. Acta Gastroenterol Belg 2017;80:317-319.

49. David O, Jakate S. Multifocal granular cell tumor of the esophagus and proximal stomach with infiltrative pattern: a case report and review of the literature. Arch Pathol Lab Med 1999;123:967-973.

50. Eguchi S, Matsuo S, Hidaka M, et al. Concomitant triple lesions of adenocarcinoma, malignant lymphoma, and granular cell tumor of the stomach. J Clin Gastroenterol 2002;35:107-109.

51. Monahan KJ, Pelling M, Goldin R, Hoare J. Endoscopic removal of a granular cell tumor from the stomach using the Duette Multiband Mucosectomy Kit. Dig Dis Sci 2010;55:2688-2690.

52. Woosley JT, Grimm I. Granular-cell tumor of the duodenum: a case report. Gastrointest Endosc 2006;63:339-341.

53. Onoda N, Kobayashi H, Satake K, et al. Granular cell tumor of the duodenum: a case report. Am J Gastroenterol 1998;93:1993-1994.

54. Roncati L, Manco G, Italia S, Barbolini G, Maiorana A, Rossi A. Granular cell tumor of the appendix: a new case and review of the literature. Springerplus 2013;2:649.

55. Sobel HJ, Marquet E, Schwarz R. Granular degeneration of appendiceal smooth muscle. Arch Pathol 1971;92:427-432.

56. Melo CR, Melo IS, Schmitt FC, Fagundes R, Amendola D. Multicentric granular cell tumor of the colon: report of a patient with 52 tumors. Am J Gastroenterol 1993;88:1785-1787.

57. Francesco VD, Avellini C, Pappalardo S, Proscia D, Piccirillo F. Malignant granular cell tumor of the anal-perianal region and suprarenal hyperplasia: a casual association? Indian J Dermatol 2010;55:403-405.

58. Cohen MG, Greenwald ML, Garbus JE, Zager JS. Granular cell tumor-a unique neoplasm of the internal anal sphincter: report of a case. Dis Colon Rectum 2000;43:1444-1446; discussion 1447.
59. AbdullGaffar B, Keloth T, Al-Hattawi M, Al Marzouqi M, ElTayeb Y. Benign anal and perianal polypoid neoplasms and tumor-like lesions. Pathol Res Pract 2012;208:719-725.

60. Mistrangelo M, Cassoni P, Scozzari G, et al. Perianal granular cell tumor: report of a case and review of the literature. Tumori 2009;95:538-541.

61. te Boekhorst DS, Gerhards MF, van Gulik TM, Gouma DJ. Granular cell tumor at the hepatic duct confluence mimicking Klatskin tumor. A report of two cases and a review of the literature. Dig Surg 2000;17:299-303.

62. Coggins RP. Granular-cell myoblastoma of common bile duct; report of a case with autopsy findings. AMA Arch Pathol 1952;54:398-402.

63. Burt A, Portmann B, Ferrell L, et al. MacSween's Pathology of the Liver. $5^{\text {th }}$ ed. Philadelphia, Pennsylvania: Elsevier; 2007. p. 608.

64. Jung C, Heo I, Kim SB, Park S, Cho SY. Biliary granular cell tumor. J Pathol Transl Med 2015;49:89-91.

65. Bilanović D, Boricić I, Zdravković D, Randjelović T, Stanisavljević N, Toković B. Granular cell tumor of the common hepatic duct presenting as cholangiocarcinoma and acute acalculous cholecystitis. Acta Chir Iugosl 2008;55:99-101.

66. Saito J, Kitagawa M, Kusanagi H, et al. Granular cell tumor of the common bile duct: a Japanese case. World J Gastroenterol 2012;18:6324-6327.

67. Hoda RS, Minamiguchi S, Lewin DN, Foody W, Weselow G, Wildi SM. Granular cell tumor of the biliary system: a report of 2 cases with cytologic diagnosis on endoscopic brushing. Acta Cytol 2005;49:199-203.

68. Karakozis S, Gongora E, Zapas JL, He P, Krishnan J, Kirkpatrick JR. Granular cell tumors of the biliary tree. Surgery 2000;128:113-115.

69. Fairchild RB, Freeman R, Salah Hammad EM, Rohrer R. Granular cell tumor with cirrhosis and transplantation. Transplantation 1999;68:315-317. 